\title{
An excursion into self-monitoring of blood glucose in children
}

\author{
Peter G. F. SwifT \\ M.A., M.R.C.P., D.C.H. \\ Leicester General Hospital, Gwendolen Road, Leicester, LE5 4PW
}

\begin{abstract}
Summary
Ten adolescent diabetic children monitored blood glucose (BG) concentrations during a British Diabetic Association holiday camp in Denmark. The range of results was wide but revealed a mean pre-breakfast (fasting) BG of $9.8 \mathrm{mmol} / \mathrm{l}$ and a mean BG before the main evening meal of $13.2 \mathrm{mmol} / \mathrm{l}$. Before the evening meal eight of ten children had BG concentrations in excess of $13 \mathrm{mmol} / \mathrm{l}$. There was a significant correlation between mean BG concentrations and glycosylated haemoglobin.

The procedure was well accepted and proved to be of considerable educational value. It clearly revealed the children whose diabetes was satisfactorily controlled and those in whom adjustments of management were required. It is suggested that similar phases of self-measurement of BG in their homes will clarify the diabetic control of many children and thus help to improve it.
\end{abstract}

\section{Introduction}

Children with diabetes are at great risk of overt vascular complications after the first decade of their disease (Leading Article, 1978). Their diabetic stability is often as erratic as their ever fluctuating life styles and, unfortunately, the traditional clinic methods of scanning urinary glucose reports or measuring random blood glucose concentrations have always been of dubious value in the assessment of control. The use of self-monitoring of blood glucose by children, along the lines proposed in adults (Sonksen, Judd, and Lowy, 1978; Walford et al., 1978; Peacock et al., 1979), might be of 'immense value in many cases and improve standards of control' (Leading Article, 1978). Children and parents might learn to understand more clearly the fluctuations of diabetes and alter insulin treatment accordingly. Furthermore, the objective measurement of glycosylated haemoglobin (Williams and Savage, 1979) following phases of self-monitoring with modifications of treatment should provide valuable information on the effectiveness of changes in management.

It has been pointed out recently that the British
Diabetic Association (BDA)-sponsored holiday camps contribute substantially to the resolution of behaviour disorders in diabetic children, possibly by the combined effects of gaining independence from parents, as increased confidence in adjusting day-today management and a release from the tensions which develop in families with a diabetic child in their midst (Editorial, 1980a).

This conclusion may be over-optimistic but a major beneficial feature of the camps should be the development of a two-way educational experience between the children and the medical officers in charge. During one of these holiday camps, therefore, a group of children was given the opportunity of monitoring blood glucose concentrations. The results of this experience are now described.

\section{Materials and methods}

Ten diabetic children ( 6 girls and 4 boys) aged 13-16 years went on a 2-week holiday to Nyborg, Denmark, in August 1979. This was organized by the BDA in close co-operation with the Danish Diabetic Association who owned the hostel, Skaerven. Except for one girl, all were on monocomponent or highly purified insulins. One boy had two small retinal haemorrhages, and one girl was overweight by more than $20 \%$. Otherwise physical examinations were normal.

During the first $48 \mathrm{hr}$ the children were asked to test their urine for glucose (as usual before meals), and at the same time to measure blood glucose (BG) concentrations by means of Dextrostix (Ames) read visually and on a Hypocount BG meter (Hypoguard Limited, Woodbridge, Suffolk). The finger-prick was performed with the aid of an automatic lancet (Autolet-Owen Mumford, Woodstock, Oxon). During this period the results were discussed with special reference to normal BG values, renal threshold and the effects of fasting, diet and exercise. After this initiation the children were offered the choice between urine and blood tests. As a group they chose to continue blood glucose measurements. They then measured BG before their 
morning and evening insulin injections and at any other time they thought it necessary or of interest to do so.

Venous blood samples for haemoglobin $\mathbf{A}_{1}$ $\left(\mathrm{HbA}_{1}\right)$ concentrations were taken at the end of the holiday and the assay performed in the haematology laboratory at Leicester Royal Infirmary by a rapid column chromatographic method (Welch and Boucher, 1978).

\section{Results}

A total of 261 measurements of BG were obtained. Each child performed a finger BG test a minimum of 21 and a maximum of 28 times over a period of 13 days. The combined results for all 10 children are shown in the table. The relationship between the mean $B G$ value and the $\mathbf{H b A}_{1}$ for each child is shown in Fig. 1. There is a significant correlation between the values (Spearman's Coefficient of Rank Correlation $r=0.648 ; P=0.05$ ). Four out of 5 children with a mean BG $>11 \mathrm{mmol} / \mathrm{l}$ also had $\mathrm{HbA}_{1}>9 \cdot 2 \%$. The fifth child with poor BG control had been unwell with mild ketosis the week preceding the holiday and perhaps the lower $\mathrm{HbA}_{1}$ in her case reflected her better overall control at home before the illness.

The average and range of $\mathrm{BG}$ results throughout

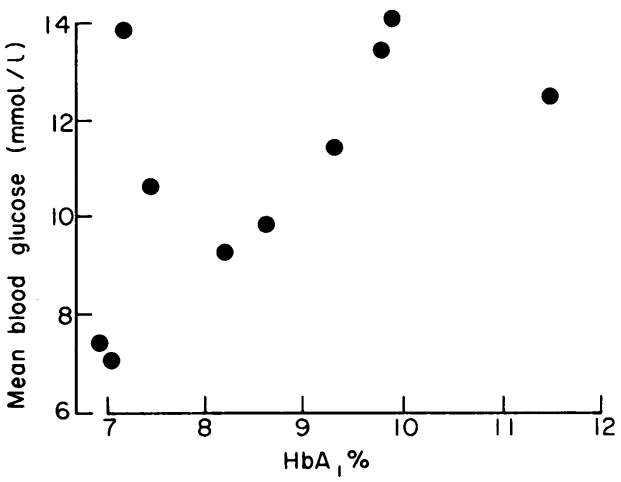

Fig. 1. The relationship between mean blood glucose and $\mathrm{HbA}_{\mathbf{1}}$.

the day obtained in two individuals are illustrated in Fig. 2 (Case 8) and Fig. 3 (Case 6). These children probably represent the best and the worst diabetic control during the holiday.

\section{Case 8}

A 16-year-old boy (weight $78 \mathrm{~kg}$ ) who was extremely active and enthusiastic, had frequent mild hypoglycaemic symptoms after exercise and indulged in daily minor dietary indiscretions. He

TABLE. Individual and combined results of blood glucose (BG) monitoring and $\mathrm{HbA}_{\mathbf{1}}$ in 10 adolescent children

\begin{tabular}{|c|c|c|c|c|c|c|c|c|}
\hline Number & Sex & Age & $\begin{array}{c}\text { Insulin } \\
\text { dose } \\
\text { (u./kg) }\end{array}$ & $\begin{array}{c}\text { Mean } \\
\text { BG } \\
(\mathrm{mmol} / \mathrm{l})\end{array}$ & $\begin{array}{r}\text { Me } \\
\text { B/fast } \\
\text { BG }\end{array}$ & $\begin{array}{l}\text { re- } \\
\text { Tea } \\
\text { BG }\end{array}$ & $\begin{array}{c}\% \text { tests } \mathrm{BG}> \\
11 \mathrm{mmol} / \mathrm{l}\end{array}$ & $\mathrm{HbA}_{1}(\%)$ \\
\hline $\begin{array}{l}1 \\
2 \\
3 \\
4 \\
5 \\
6 \\
7 \\
8 \\
9 \\
10 \\
\text { Mean }\end{array}$ & $\begin{array}{l}\mathbf{F} \\
\mathbf{F} \\
\mathbf{F} \\
\mathbf{F} \\
\mathbf{F} \\
\mathbf{F} \\
\mathbf{M} \\
\mathbf{M} \\
\mathbf{M} \\
\mathbf{M}\end{array}$ & $\begin{array}{l}15 \\
13 \\
14 \\
13 \\
15 \\
15 \\
15 \\
16 \\
15 \\
15 \\
14 \cdot 6\end{array}$ & $\begin{array}{l}0.87 \\
1.45 \\
0.88 \\
0.39 \\
0.80 \\
0.88 \\
1.36 \\
1.13 \\
0.71 \\
0.65 \\
0.91\end{array}$ & $\begin{array}{r}10 \cdot 7 \\
7 \cdot 4 \\
13 \cdot 4 \\
13 \cdot 9 \\
14 \cdot 0 \\
12 \cdot 4 \\
9 \cdot 7 \\
7 \cdot 1 \\
9 \cdot 2 \\
11 \cdot 4 \\
10 \cdot 9\end{array}$ & $\begin{array}{r}9 \cdot 0 \\
9.3 \\
12.4 \\
16.5 \\
9 \cdot 4 \\
10 \cdot 1 \\
9.0 \\
8.4 \\
4 \cdot 1 \\
10.2 \\
9.8\end{array}$ & $\begin{array}{r}15 \cdot 2 \\
8 \cdot 1 \\
14 \cdot 1 \\
13 \cdot 2 \\
17 \cdot 7 \\
15 \cdot 7 \\
13 \cdot 7 \\
6 \cdot 9 \\
13 \cdot 8 \\
14 \cdot 5 \\
13 \cdot 2\end{array}$ & $\begin{array}{l}42 \\
19 \\
61 \\
71 \\
58 \\
68 \\
38 \\
14 \\
29 \\
46 \\
44\end{array}$ & $\begin{array}{r}7.4 \\
6.9 \\
9.7 \\
7 \cdot 2 \\
9.9 \\
11 \cdot 5 \\
8.6 \\
7 \cdot 0 \\
8 \cdot 2 \\
9.3 \\
8.6\end{array}$ \\
\hline
\end{tabular}

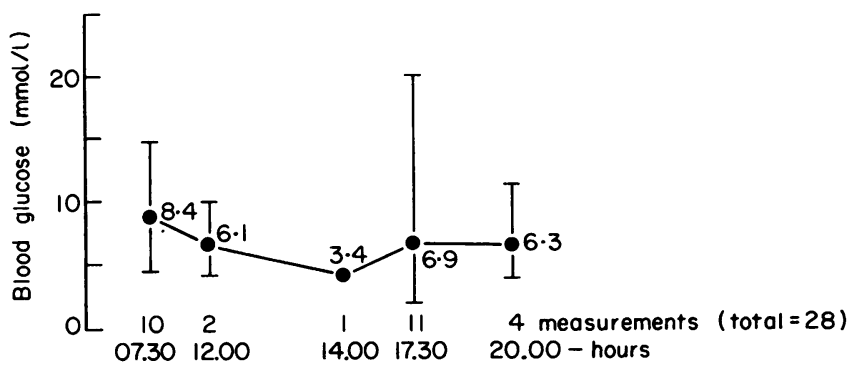

Fig. 2. Mean and range of daily blood glucose results (case 8), 


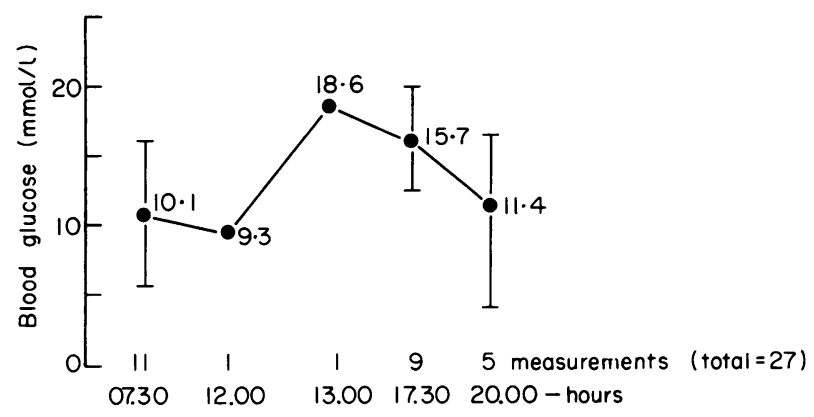

Fig. 3. Mean and range of daily blood glucose results (case 6).

was the only child on a single injection of insulin which consisted of a large dose of Monotard 48 units mixed with Actrapid 44 units each morning (i.e. $1 \cdot 13 \mathrm{u} . / \mathrm{kg}$ ). His mean $\mathrm{BG}$ and $\mathrm{HbA}_{1}$ were $7 \cdot 1 \mathrm{mmol} / \mathrm{l}$ and $8.5 \%$ respectively.

\section{Case 6}

A 15 -year-old girl was more than $20 \%$ overweight. She was lethargic, difficult to motivate, very selfconscious and was used to eating regular meals which contained excess calories in relation to her energy expenditure. Despite an increase in her insulin from 0.88 to $1.35 \mathrm{u} . / \mathrm{kg}$ her blood glucose control remained unsatisfactory. Her mean BG and $\mathrm{HbA}_{1}$ were $12.4 \mathrm{mmol} / \mathrm{l}$ and $12 \%$ respectively.

\section{Discussion}

There were few complaints of sore fingers and most of the children expressed the view that the immediate knowledge of BG concentrations at the time of testing was important in understanding the variability of their control and the factors which influenced changes in BG levels. Obviously this was an artificial and temporary environment for them and they tended to respond as a group, but when they saw their BG rising after dietary indiscretions and falling to satisfactory levels after exercise they gained greater insight into their disease. Regular measurements of BG revealed those children who were well controlled and seemed to give an accurate assessment of the degree of suboptimal control in at least 5 of the children. Only three nocturnal hypoglycaemic episodes were recorded.

One child, who in the past had been poorly controlled, had been introduced to self-monitoring (by visual Dextrostix estimations) at the camp 12 months previously and became highly motivated with moderately good overall control (mean BG 9.7; $\mathrm{HbA}_{1} 8.7 \%$ ). At least two other children wished to continue monitoring their blood sugars on returning home and have purchased blood glucose meters.
Two of the least well controlled children lacked 3 the initiative and desire to improve. They tended to be physically less active and despite attempts at altering the diet and changing insulin doses during $ᄏ$ the holiday they did not clearly show improved BG profiles. Four children had BG values of more than $11 \mathrm{mmol} / 1$ on more than $50 \%$ of occasions and the concentrations were sometimes $>25 \mathrm{mmol} / \mathrm{l}$.

These disappointing results confirm the well recognized fact that unless diabetic patients (or their parents or physicians) are enthusiastic about achieving good control, self-monitoring by itself wi $\vec{\oplus}$ not alter this situation (Editorial, 1980b). Howeves ? two other children with very erratic BG profile improved with the addition of longer acting insulinst to their regimes.

Although epidemiological studies have shown that if $B G$ values do not rise above $11 \mathrm{mmol} / \mathrm{l}$ after a a $50 \mathrm{~g}$ glucose load, the risks of microangiopathic complications are reduced (Jarrett and Keen, 1976; Bennett et al., 1976) in insulin-dependent diabetics, optimal BG control should aim at considerably lower values than this, particularly before meals (Jarrett and Keen, 1980). It is worrying, therefore, that 8 out of the 10 children had mean pre-tea BG concentrations above $13 \mathrm{mmol} / \mathrm{l}$. Tighter control may render children more liable to hypoglycaemic attacks, but the two boys in this group who experienced mild hypoglycaemia on exercise seemed to accept or tolerate this well and certainly better than do children who have wild swings of glucose concentrations. It remains to be seen whether relative normoglycaemia with more fre- $\mathcal{O}$ quent hypoglycaemic episodes are more damaging $N$ in the long-term than constant mild or moderate $\mathrm{C}_{\mathrm{W}}$ hyperglycaemia.

This study has shown that blood glucose measure- $\stackrel{0}{2}$ ments in a group of children on a BDA holiday $\stackrel{\circ}{C}$

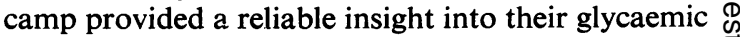
control. The finger prick BG measurements were performed in a satisfactory manner and the technique was accepted with enthusiasm. This experience 
suggests that diabetic children should be given the opportunity of measuring BG concentrations at home in an attempt to improve diabetic control. It is likely that frequent daily measurements would become as tedious to children as do the routine twice a day urine tests. Therefore, short phases of BG monitoring paying particular attention to insulin doses and exercise during these phases would seem to be the most practical way of applying the BG monitoring technique to children and their families.

\section{Acknowledgments}

I would like to thank the British Diabetic Association for organizing this holiday and the Danish Diabetic Association for allowing us to stay at Skaerven. I acknowledge the help of Dr J. K. Wood and Mr J. O'Connor in the Haematology Department, Leicester Royal Infirmary, for the $\mathbf{H b A}_{1}$ measurements.

\section{References}

Bennett, P.H., Rushforth, N.B., Millet, M. \& Le Comte, P. (1976) Epidemiologic studies in diabetes in the Pima Indians. Recent Progress in Hormone Research, 32, 333.
Editorial (1978) Diabetic control at night. Lancet, ii, 297.

EDITORIAL (1980a) Behavioural disorders in diabetic children. Lancet, ii, 188.

EDITORIAL (1980b) Home blood-glucose monitoring: revolution, revelation or rip-off? Lancet, ii, 187.

JARRETT, R.J. \& KEEN, H. (1976) Hyperglycaemia and diabetes mellitus. Lancet, ii, 1009.

JARRETT, R.J. \& KeEN, H. (1980) Towards a target bloodglucose in diabetes. Lancet, ii, 30 .

LeADING ARTICLE (1978) Diabetic complications in childhood. British Medical Journal, i, 941.

Peacock, I., Hunter, J.C., Walford, S., Allison, S.P., Davison, J., Clarke, P, Symonds, E.M. \& Tattersall, R.B. (1979) Self-monitoring of blood glucose in diabetic pregnancy. British Medical Journal, 2, 1333.

Sonksen, P.H., Judd, S.L. \& Lowy, C. (1978) Home monitoring of blood-glucose. Method of improving diabetic control. Lancet, i, 729.

Walford, S., Gale, E.A.M., Allison, S.P. \& Tattersall, R.B. (1978) Self-monitoring of blood glucose. Improvement of diabetic control. Lancet, i, 732.

WELCH, S.G. \& BouChER, B.J. (1978) A rapid micro-scale method for the measurement of haemoglobin $A_{1(a+b+c)}$ Diabetologia 14, 209.

Williams, M.L. \& Savage, D.C.L. (1979) Glycosylated haemoglobin levels in children with diabetes mellitus. Archives of Disease in Childhood, 54, 295. 